Acta Crystallographica Section C

Crystal Structure

Communications

ISSN 0108-2701

\section{Four stereoisomers of the novel $\mu$-opioid receptor agonist tapentadol hydrochloride}

\section{Krishnan Ravikumar, ${ }^{\mathrm{a} *}$ Balasubramanian Sridhar, ${ }^{\mathrm{a}}$ Nitin Pradhan $^{b}$ and Mayur Khunt ${ }^{b}$}

a Laboratory of X-ray Crystallography, Indian Institute of Chemical Technology, Hyderabad 500 007, India, and ${ }^{\mathbf{b}}$ Research and Development Centre, Actavis Pharmaceutical Development Centre Pvt. Ltd, Bangalore 560 034, India Correspondence e-mail: sshiya@yahoo.com

Received 26 October 2010

Accepted 12 January 2011

Online 20 January 2011

The crystal and molecular structures of four stereoisomers of tapentadol hydrochloride [systematic name: 3-(3-hydroxyphenyl)- $N, N, 2$-trimethylpentan-1-aminium chloride], $\mathrm{C}_{14} \mathrm{H}_{24^{-}}$ $\mathrm{NO}^{+} \cdot \mathrm{Cl}^{-}$, a novel analgesic agent, have been determined by $\mathrm{X}$-ray crystal structure analysis. Resolution of the isomers was carried out by reverse-phase and chiral high-performance liquid chromatographic (HPLC) methods. Stereoisomers (I) and (II) crystallize in the monoclinic space group $P 2_{1}$, each with two tapentadol cations and two chloride anions in the asymmetric unit, while stereoisomers (III) and (IV) crystallize in the orthorhombic space group $P 2{ }_{1} 2{ }_{1} 2$, with one tapentadol cation and one chloride anion in the asymmetric unit. The absolute configurations of the four enantiomers were determined unambiguously by X-ray crystallography. The crystal structures reveal the stereochemistries at the 3-ethyl and 2-methyl groups to be $R, R, S, S, S, R$ and $R, S$ in stereoisomers (I)-(IV), respectively. The ethyl and aminopropyl groups adopt different orientations with respect to the phenol ring for (I) and (IV). In all four structures, the chloride ions take part in $\mathrm{N}-\mathrm{H} \cdots \mathrm{Cl}$ and $\mathrm{O}-\mathrm{H} \cdots \mathrm{Cl}$ hydrogen bonds with the tapentadol molecules, resulting in one-dimensional helical chains in the crystal packing in each case.

\section{Comment}

Tapentadol is a novel centrally acting synthetic analgesic with a unique profile of action for the treatment of moderate to severe pain (Tzschentke et al., 2007). It acts in two ways, viz. opioid (narcotic) and non-opioid. Tapentadol affects the brain and body primarily by activating opioid receptors in the brain, spinal cord and gastrointestinal tract. In addition, it inhibits the re-uptake of the brain chemical norepinephrine which possibly has an analgesic effect. Tapentadol is being developed in immediate-release and extended-release formulations (Etropolski et al., 2010).
The United States Food and Drug Administration (US FDA) approved tapentadol hydrochloride in 2008 as an immediate-release oral tablet for the relief of moderate to severe acute pain, both cancer-related and other. Tapentadol is manufactured by Janssen Ortho LLC, Gurabo, Puerto Rico, USA, and was initially developed by Grunenthal $\mathrm{GmbH}$, Aachen, Germany, in conjunction with Johnson \& Johnson Pharmaceutical Research and Development. We report here the crystal structures of four stereoisomers of tapentadol hydrochloride, (I)-(IV), as part of our ongoing study of the structural characterization of drug molecules (Ravikumar \& Sridhar, 2009, 2010).<smiles>[H][Y9]([H])(C)C[C@@H](C)[C@H](CC)c1cccc(O)c1</smiles><smiles>CC[C@H](C[NH+](C)C)[C@H](C)c1cccc(O)c1</smiles><smiles>C[C@H](CC[NH+](C)C)c1cccc(O)c1</smiles><smiles>[H][Y9](C)(C)C[C@H](C)[C@H](CC)c1cccc(O)c1</smiles><smiles>CCOCCOCCN(C)C[C@@H]1CCCC[C@@]1(O)c1cccc(OC)c1</smiles><smiles>COc1ccc([C@](C)(CN(C)C)C2(O)CCCC2)cc1</smiles>

Resolution of the four isomers was carried out using reverse-phase and chiral high-performance liquid chromatography (HPLC) methods; compounds (I)-(IV) showed good resolution in HPLC analysis and diastereomeric isomer separation in reverse-phase HPLC analysis. The purities of all individual isomers were confirmed by both chiral and reversephase HPLC. In the chiral method, isomers (I), (II), (III) and (IV) eluted at retention times of 19.21, 24.56, 17.81 and $16.61 \mathrm{~min}$, respectively (Fig. 1), whereas in the reverse-phase method, the retention times were 17.00, 17.21, 15.58 and

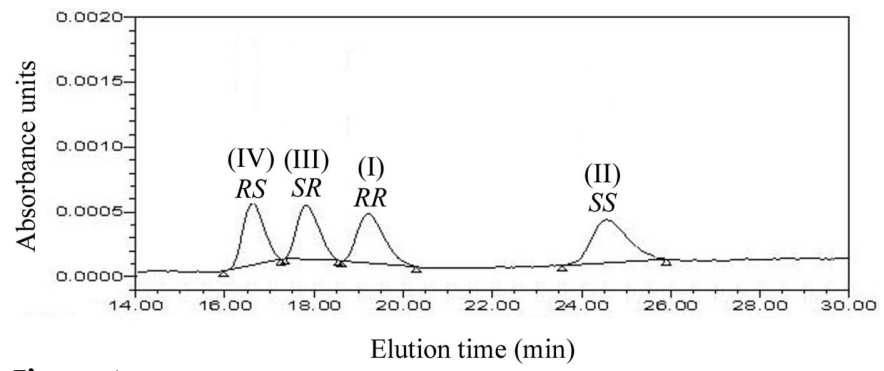

Figure 1

Chiral HPLC profiles of the four stereoisomers of tapentadol hydrochloride, using a CHIRALPAK AD-3 $(250 \times 4.6 \mathrm{~mm} \times 5 \mu \mathrm{m})$ column and an 85:15 $(v / v)$ hexane-tetrahydrofuran solvent system. 


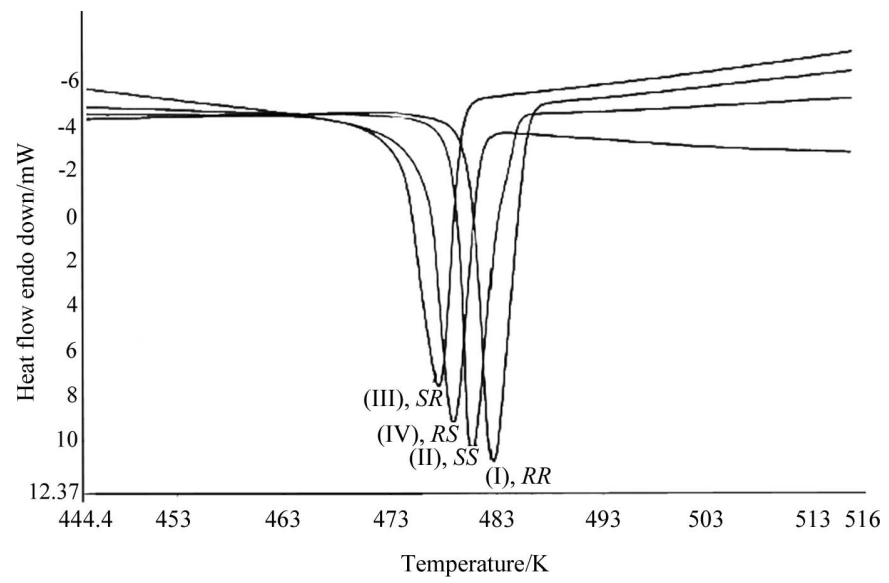

Figure 2

Comparative differential scanning calorimetric (DSC) thermographs for the four stereoisomers of tapentadol hydrochloride.

$15.48 \mathrm{~min}$, respectively. It can be seen that isomers (I) and (II) are one pair of enantiomers, and isomers (III) and (IV) are a second pair, having similar retention times in reverse-phase HPLC analysis.

Differential scanning calorimetric (DSC) measurements were carried out using a Perkin-Elmer Diamond DSC apparatus. Experiments were performed at a heating rate of $10.0 \mathrm{~K} \mathrm{~min}^{-1}$ over a temperature range of 303-533 $\mathrm{K}$ under a nitrogen flow of $50 \mathrm{ml} \mathrm{min}{ }^{-1}$. The DSC curves for (I)-(IV) show sharp endothermic peaks, corresponding to melting points, at 482, 480, 477 and $478 \mathrm{~K}$ for isomers (I)-(IV), respectively (Fig. 2).

Tapentadol consists of a meta-substituted phenol ring possessing an ethyl and an aminopropyl residue at C7. It has two stereogenic centres, at $\mathrm{C} 7$ and $\mathrm{C} 10$, which results in four possible diastereomers; the $R, R$ isomer is currently the clinically used form (Franklin et al., 2010). Tapentadol is structurally the closest chemical relative of tramadol in clinical use. Both tramadol and venlafaxine are racemic mixtures (Reeves \& Cox, 2008), whereas tapentadol represents only one stereoisomer, viz. $(1 R, 2 R)$. Structurally, tapentadol differs from tramadol in being a phenol and not an ether. Also, both tramadol and venlafaxine incorporate a cyclohexyl group attached directly to the aromatic ring, while tapentadol lacks this feature.

The crystal structures of isomers (I) and (II) are enantiomorphs, crystallizing in the space group $P 2_{1}$. Similarly, the crystal structures of isomers (III) and (IV) are also enantiomorphs, but crystallizing in the space group $P 2_{1} 2_{1} 2_{1}$. Thus, (I)/ (III) and (II)/(IV) are pairs of diastereomers. Unambiguous determination of the absolute configurations of all four structures was carried out by means of refinement of the Flack parameter (Flack \& Bernardinelli, 2000). It was therefore assigned that (I) is the $R, R$ enantiomer and (II) is the $S, S$ enantiomer, with melting points of $482-483$ and $480-481 \mathrm{~K}$, respectively. It was also found that (III) is the $S, R$ isomer and (IV) is the $R, S$ isomer, with melting points of 477-478 and 478$479 \mathrm{~K}$, respectively, from the above-mentioned DSC studies. Each asymmetric unit in (I) and (II) comprises two tapentadol

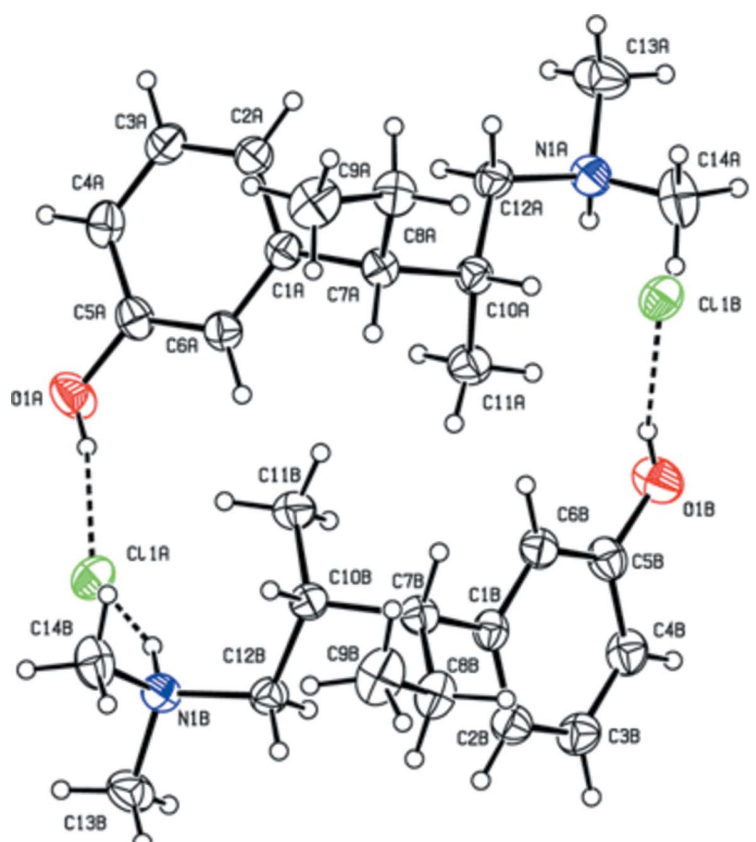

(a)

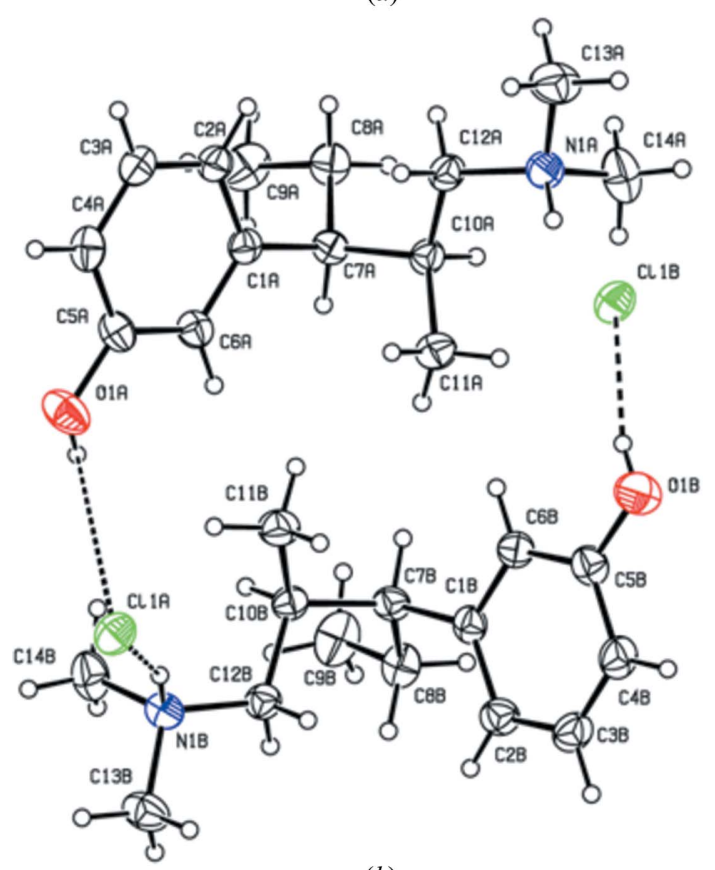

(b)

Figure 3

Views of $(a)$ (I) and (b) (II), showing the atom-numbering schemes. Displacement ellipsoids are drawn at the $50 \%$ probability level. Dashed lines indicate hydrogen bonds.

cations and two chloride anions (Fig. 3). In the case of (III) and (IV), the asymmetric unit consists of one tapentadol cation and one chloride anion (Fig. 4).

The geometric parameters of (I)-(IV) are similar. However, there are significant angular variations observed between the two independent molecules of (I) and (II) involving the chiral atom $\mathrm{C} 7$, the differences being $\mathrm{C} 7-\mathrm{C} 8-\mathrm{C} 9=2.5$ (2) [in (I)] and $2.7(2)^{\circ}$ [in (II)], and $\mathrm{C} 8-\mathrm{C} 7-\mathrm{C} 10=2.1$ (1) [in (I)] and $2.3(2)^{\circ}$ [in (II)] (Table 1). This may perhaps be attributed to the syn/anti conformers found around the $\mathrm{C} 8-\mathrm{C} 9$ bond. 


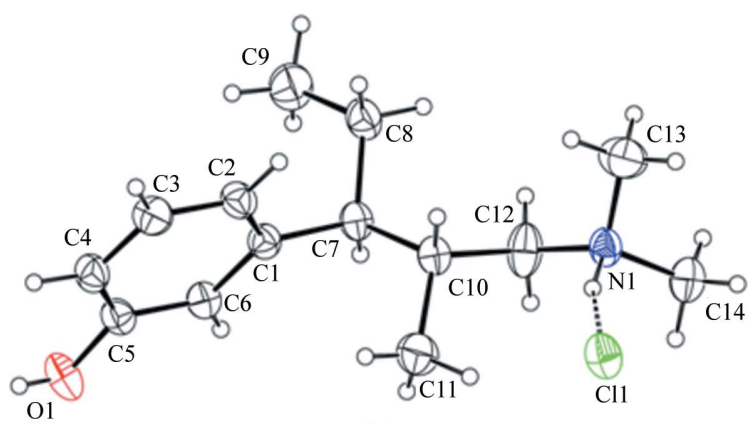

(a)

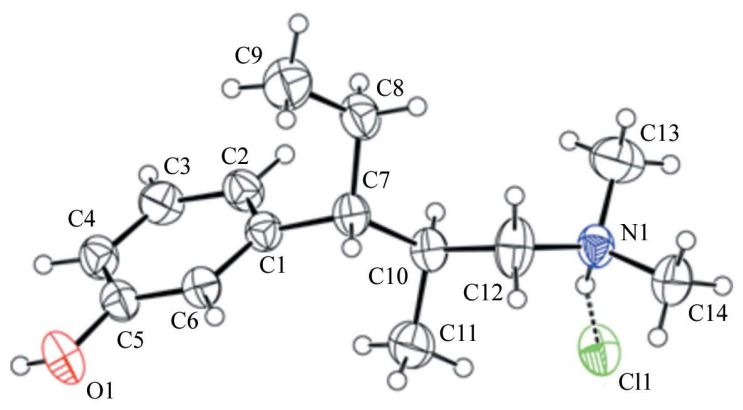

(b)

Figure 4

Views of (a) (III) and (b) (IV), showing the atom-numbering schemes. Displacement ellipsoids are drawn at the $50 \%$ probability level. Dashed lines indicate hydrogen bonds.

The aminopropyl and ethyl groups are located on opposite sides of the plane defined by the aromatic ring. The two cations in asymmetric unit of (I), although constructed from molecules with the same chirality, are paired around a pseudocentre of symmetry at $\left(\frac{1}{4}, 0.65, \frac{3}{4}\right)$ and differ significantly in the orientation of atom C9 of the ethyl group. The orientation of the ethyl group with respect to the phenol ring can be seen from the torsion angle $\mathrm{C} 1-\mathrm{C} 7-\mathrm{C} 8-\mathrm{C} 9$, which is $c$ is in molecule $A$ of (I) and trans in molecule $B$, while in (III) it adopts a cis orientation. The conformation of the aminopropyl group can be defined from the $\mathrm{C}-\mathrm{C}-\mathrm{C}-\mathrm{C}$ and $\mathrm{C}-\mathrm{C}-\mathrm{C}-\mathrm{N}$ torsion angles, and the conformation is cis-trans for both molecules of (I), while it is trans-trans for (III) (Table 1). An overlay of the tapentadol molecules, superimposing atoms $\mathrm{C} 1-\mathrm{C} 7$ of the phenol ring system, reveals the differences in

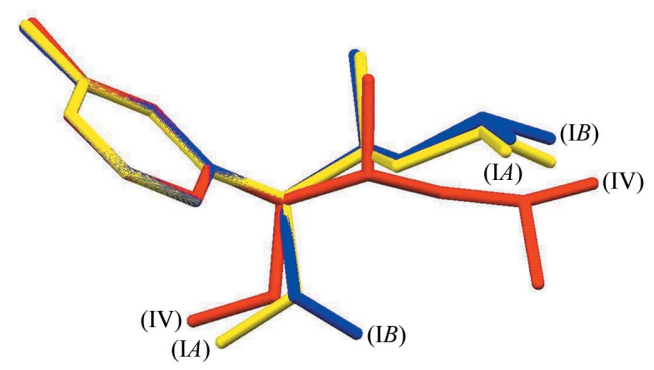

Figure 5

Superposition of the molecular conformations of the tapentadol molecules of (I) and (IV), showing the orientations of the ethyl and aminopropyl groups with respect to the phenol ring. The overlay was made by making a least-squares fit through the planar phenol ring (atoms C1-C7) of tapentadol [molecules (IA) and (IB)] and (IV).

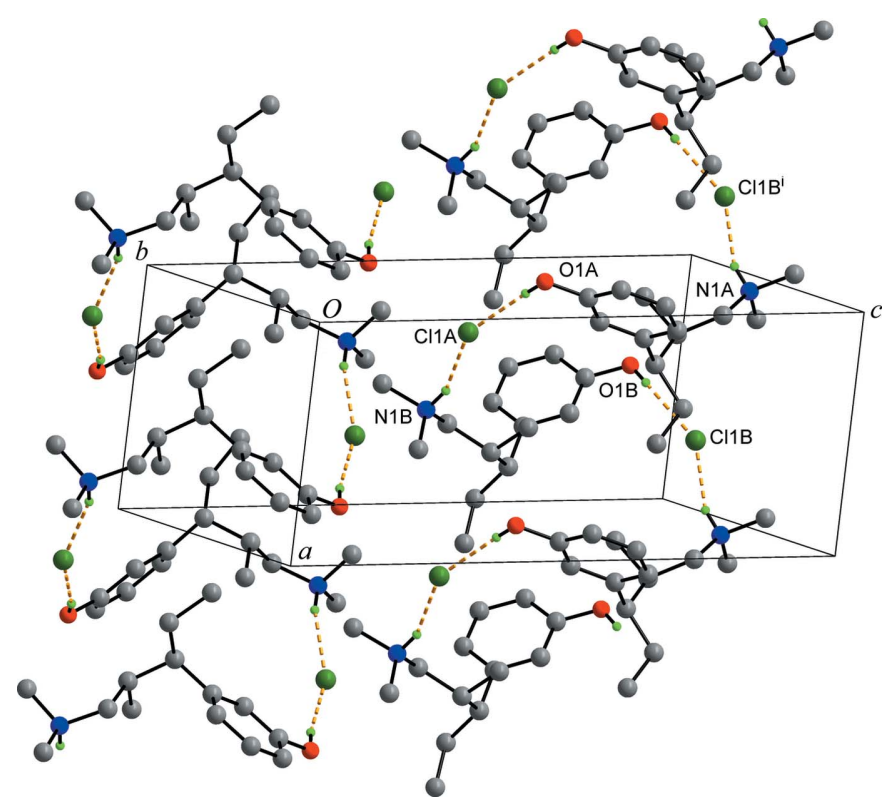

Figure 6

Part of the crystal packing for (I), showing the involvement of the chloride ions in $\mathrm{N}-\mathrm{H} \cdots \mathrm{Cl}$ and $\mathrm{O}-\mathrm{H} \cdots \mathrm{Cl}$ hydrogen bonds with the tapentadol molecules, resulting in a one-dimensional helical chain along the $a$ axis. Hydrogen bonds are shown as dashed lines and $\mathrm{H}$ atoms not involved in hydrogen bonding have been omitted for clarity. Only atoms involved in hydrogen bonding have been labelled. [Symmetry code: (i) $x-1, y, z$.]

orientation of both the ethyl and aminopropyl groups with respect to the phenol ring (Fig. 5). It is interesting to note that the ethyl group of (III) adopts a similar conformation to molecule (IA), while the conformation of the aminopropyl group is entirely different from (I). This difference might influence the participation of the aminopropyl group in $\mathrm{C}-$ $\mathrm{H} \cdots \mathrm{Cl}$ interactions in (III), which are absent in (I).

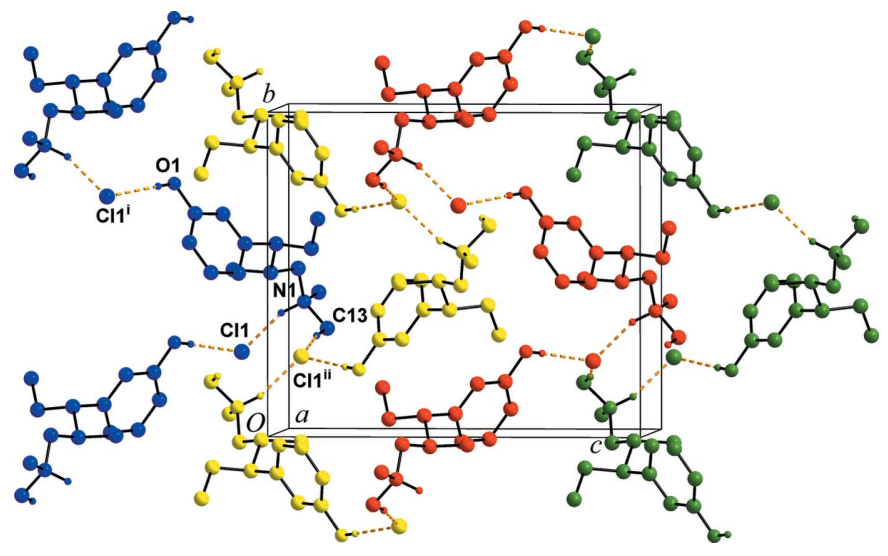

Figure 7

Part of the crystal packing for (III), showing the helical chains of tapentadol molecules linked by the chloride ions via $\mathrm{N}-\mathrm{H} \cdots \mathrm{Cl}$ and $\mathrm{O}-$ $\mathrm{H} \cdots \mathrm{Cl}$ hydrogen bonds. Also shown are the helical chains interlinked by $\mathrm{C}-\mathrm{H} \cdots \mathrm{Cl}$ hydrogen bonds. Hydrogen bonds are shown as dashed lines and $\mathrm{H}$ atoms not involved in hydrogen bonding have been omitted for clarity. Only atoms involved in hydrogen bonding have been labelled. [Symmetry codes: (i) $-x+2, y+\frac{1}{2},-z+\frac{1}{2}$; (ii) $x+\frac{1}{2},-y-\frac{1}{2},-z$.] 
The crystal structures of the four stereoisomers, (I)-(IV), feature $\mathrm{N}-\mathrm{H} \cdots \mathrm{Cl}$ and $\mathrm{O}-\mathrm{H} \cdots \mathrm{Cl}$ hydrogen bonds (Tables 2-5) between the chloride ions and the amino and hydroxy groups of the tapentadol molecules. Each chloride ion accepts two hydrogen bonds from the amino and hydroxy groups of the tapentadol molecules and forms a one-dimensional helical chain. In (I) and (II), the helical chain is along the $a$ axis (Fig. 6), while in (III) and (IV) it is along the $b$ axis (Fig. 7). Furthermore, in (III) and (IV) $\mathrm{C}-\mathrm{H} \cdots \mathrm{Cl}$ interactions link the helical chains to adjacent chains.

\section{Experimental}

(2R,3R)-3-(3-Hydroxyphenyl)- $N, N, 2$-trimethylpentan-1-aminium chloride, (I), was prepared as follows. $(2 R, 3 S)$-1-Dimethylamino-3-(3hydroxyphenyl)-2-methylpentan-3-ol tartaric acid salt (35 g, $1 \mathrm{~mol}$ ) and water $(150 \mathrm{ml})$ were placed in a round-bottomed flask and an aqueous ammonia solution $(30 \mathrm{ml})$ was added to obtain a basic $\mathrm{pH}$, followed by extraction into dichloromethane $(150 \mathrm{ml})$ at $293-298 \mathrm{~K}$. The organic layer was separated, dried over anhydrous sodium sulfate and concentrated under reduced pressure to afford an oil. 2-Methyltetrahydrofuran $(300 \mathrm{ml})$ and trifluoroacetic anhydride $(50 \mathrm{ml})$ were added to this oil at $293-298 \mathrm{~K}$. The mixture was transferred to an autoclave, $\mathrm{Pd} / \mathrm{C}(9 \mathrm{~g}, 10 \% \mathrm{Pd}, 50 \%$ wet $)$ was added and a hydrogen pressure ( 5 to $7 \mathrm{~kg} \mathrm{~cm}^{-2} ; 1 \mathrm{~kg} \mathrm{~cm}^{-2}=98066.5 \mathrm{~Pa}$ ) was applied. The reaction mixture was heated to $318-323 \mathrm{~K}$ for $5 \mathrm{~h}$. After cooling, the reaction mass was filtered through Celite Hyflo Super Cel and the filtrate was distilled under vacuum at 318-323 K to obtain an oil, to which water $(150 \mathrm{ml})$ and aqueous ammonia $(30 \mathrm{ml})$ were added. The aqueous layer was extracted using dichloromethane $(150 \mathrm{ml})$ and the organic layer was separated, dried over anhydrous sodium sulfate and concentrated under vacuum at $308-313 \mathrm{~K}$ to obtain an oil. Propan-2-ol (100 ml) and propan-2-ol-HCl (30 ml, pH 1-2) were added to this oil and the mixture stirred for $1 \mathrm{~h}$ at 293 $298 \mathrm{~K}$. The resulting slurry was cooled to $273-278 \mathrm{~K}$ for $1 \mathrm{~h}$. The solid was filtered off and washed with propan-2-ol $(30 \mathrm{ml})$, and then dried in an air oven at $328 \mathrm{~K}$ for $10-12 \mathrm{~h}$. The solid was then recrystallized from butanone to yield a white solid. Purity by HPLC: $99.53 \%$; m.p. $482-483 \mathrm{~K} ;{ }^{1} \mathrm{H}$ NMR $\left(\mathrm{D}_{2} \mathrm{O}\right): \delta 0.54\left(t, 3 \mathrm{H},-\mathrm{CH}_{2}-\mathrm{CH}_{3}\right), 0.96(d, 3 \mathrm{H},-$ $\left.\mathrm{CH}-\mathrm{CH}_{3}\right), 1.42,1.73\left(m, 2 \mathrm{H},-\mathrm{CH}_{2}-\mathrm{CH}_{3}\right), 2.04(m, 1 \mathrm{H},-\mathrm{CH}-$ Ethyl), $2.20\left(m, 1 \mathrm{H},-\mathrm{CH}-\mathrm{CH}_{3}\right), 2.61\left[s, 6 \mathrm{H},-\mathrm{N}(\mathrm{Me})_{2}\right], 2.70,2.74(m$, $\left.2 \mathrm{H},-\mathrm{CH}_{2}\right), 6.62(d, 1 \mathrm{H}, \mathrm{Ar}-\mathrm{H}), 6.69(d d, 2 \mathrm{H}, \mathrm{Ar}-\mathrm{H}), 7.13(t, 1 \mathrm{H}$, $\mathrm{Ar}-\mathrm{H})$; MS: $m / z 221\left(M^{+}\right)$.

(2S,3S)-3-(3-Hydroxyphenyl)- $N, N, 2$-trimethylpentan-1-aminium chloride, (II), was prepared as follows. Using (2S,3R)-1-dimethylamino-3-(3-hydroxyphenyl)-2-methylpentan-3-ol tartaric acid salt, $(25 \mathrm{~g}, 1 \mathrm{~mol})$, the above process was followed to obtain (II). It was recrystallized from butanone to yield a white solid. Purity by HPLC: 99.85\%; m.p. 480-481 K; ${ }^{1} \mathrm{H}$ NMR $\left(\mathrm{D}_{2} \mathrm{O}\right): \delta 0.55\left(t, 3 \mathrm{H},-\mathrm{CH}_{2}-\mathrm{CH}_{3}\right)$, $0.97\left(d, 3 \mathrm{H},-\mathrm{CH}-\mathrm{CH}_{3}\right), 1.45,1.74\left(m, 2 \mathrm{H},-\mathrm{CH}_{2}-\mathrm{CH}_{3}\right), 2.06(m, 1 \mathrm{H}$, -CH-Ethyl), $2.23\left(m, 1 \mathrm{H},-\mathrm{CH}-\mathrm{CH}_{3}\right), 2.65\left[s, 6 \mathrm{H},-\mathrm{N}(\mathrm{Me})_{2}\right], 2.70$, $2.78\left(m, 2 \mathrm{H},-\mathrm{CH}_{2}\right), 6.64(d, 1 \mathrm{H}, \mathrm{Ar}-\mathrm{H}), 6.69(d d, 2 \mathrm{H}, \mathrm{Ar}-\mathrm{H}), 7.15$ $(t, 1 \mathrm{H}, \mathrm{Ar}-\mathrm{H})$; MS: $m / z 221\left(M^{+}\right)$.

(2R,3S)-3-(3-Hydroxyphenyl)- $N, N, 2$-trimethylpentan-1-aminium chloride, (III), was prepared as follows. Toluene $(160 \mathrm{ml})$, aluminium chloride $(45.3 \mathrm{~g})$ and thiourea $(20 \mathrm{~g})$ were placed in a roundbottomed flask and stirred at $293-298 \mathrm{~K}$ for $30 \mathrm{~min}$. $(2 R, 3 S)-1-$ Dimethylamino-3-(3-methoxyphenyl)-2-methylpentane (20 g, $1 \mathrm{~mol}$ ) was dissolved in toluene $(40 \mathrm{ml})$. This solution was added to the above mixture at $293-298 \mathrm{~K}$ and the combined mixture heated at
$383-388 \mathrm{~K}$ for $6 \mathrm{~h}$. After cooling, water $(50 \mathrm{ml})$ and aqueous ammonia (100 ml) were added, and the mixture was filtered through Hyflo and the organic layer separated. The aqueous layer was extracted with toluene $(100 \mathrm{ml})$. The combined organic layers were washed with water $(100 \mathrm{ml})$, dried over anhydrous sodium sulfate and concentrated under vacuum at 323-328 K to obtain an oil. Propan-2ol $(50 \mathrm{ml})$ and propan-2-ol- $\mathrm{HCl}(30 \mathrm{ml}, \mathrm{pH} 1-2)$ were added to this oil and the mixture was stirred for $2 \mathrm{~h}$ at $273-278 \mathrm{~K}$. The solid was then filtered off, washed with propan-2-ol $(10 \mathrm{ml})$, dried under vacuum at $313-318 \mathrm{~K}$ for $2 \mathrm{~h}$ and recrystallized from butanone to yield a white solid (m.p. 477-478 K). ${ }^{1} \mathrm{H}$ NMR $\left(\mathrm{D}_{2} \mathrm{O}\right): \delta 0.60(t, 3 \mathrm{H}$, $\left.\mathrm{CH}_{2}-\mathrm{CH}_{3}\right), 0.75\left(d, 3 \mathrm{H},-\mathrm{CH}-\mathrm{CH}_{3}\right), 1.57\left(m, 2 \mathrm{H},-\mathrm{CH}_{2}-\mathrm{CH}_{3}\right), 2.10$ ( $m, 1 \mathrm{H},-\mathrm{CH}-\mathrm{Ethyl}), 2.35\left(p, 1 \mathrm{H},-\mathrm{CH}-\mathrm{CH}_{3}\right), 2.72\left[s, 6 \mathrm{H},-\mathrm{N}(\mathrm{Me})_{2}\right]$, $3.09\left(d d, 2 \mathrm{H},-\mathrm{CH}_{2}\right), 6.62(d, 1 \mathrm{H}, \mathrm{Ar}-\mathrm{H}), 6.69(d d, 2 \mathrm{H}, \mathrm{Ar}-\mathrm{H}), 7.13$ $(t, 1 \mathrm{H}, \mathrm{Ar}-\mathrm{H})$; MS: $m / z 221\left(M^{+}\right)$.

(2S,3R)-3-(3-Hydroxyphenyl)- $N, N, 2$-trimethylpentan-1-aminium chloride, (IV), was prepared as follows. (2S,3R)-1-Dimethylamino-3(3-methoxyphenyl)-2-methylpentane (12 g, $1 \mathrm{~mol}$ ) and aqueous $\mathrm{HBr}$ $(80 \mathrm{ml})$ were placed in a round-bottomed flask at $293-298 \mathrm{~K}$. The reaction mass was heated to $373 \mathrm{~K}$ for $15-16 \mathrm{~h}$. After cooling, water $(200 \mathrm{ml})$, ice $(200 \mathrm{~g})$ and aqueous ammonia $(200 \mathrm{ml})$ were added to the reaction mass at $278-283 \mathrm{~K}$. The product was extracted with dichloromethane $(400 \mathrm{ml})$ and the organic layer was separated, dried over anhydrous sodium sulfate and concentrated under vacuum at $308-313 \mathrm{~K}$ to obtain an oil. Propan-2-ol $(100 \mathrm{ml})$ and propan-2-ol$\mathrm{HCl}(20 \mathrm{ml}, \mathrm{pH} 1-2)$ were added to this oil and the mixture stirred for $2 \mathrm{~h}$ at $273-278 \mathrm{~K}$. The solid was then filtered off, washed with propan2-ol ( $25 \mathrm{ml})$, dried in an air oven at 323-328 $\mathrm{K}$ and recrystallized from butanone to yield a white solid (m.p. $478-479 \mathrm{~K}) .{ }^{1} \mathrm{H}$ NMR $\left(\mathrm{D}_{2} \mathrm{O}\right): \delta$ $0.61\left(t, 3 \mathrm{H},-\mathrm{CH}_{2}-\mathrm{CH}_{3}\right), 0.75\left(d, 3 \mathrm{H},-\mathrm{CH}-\mathrm{CH}_{3}\right), 1.59(m, 2 \mathrm{H},-$ $\left.\mathrm{CH}_{2}-\mathrm{CH}_{3}\right), 2.10(m, 1 \mathrm{H},-\mathrm{CH}-\mathrm{Ethyl}), 2.36\left(p, 1 \mathrm{H},-\mathrm{CH}-\mathrm{CH}_{3}\right), 2.73$ $\left[s, 6 \mathrm{H},-\mathrm{N}(\mathrm{Me})_{2}\right], 3.09\left(d d, 2 \mathrm{H},-\mathrm{CH}_{2}\right), 6.63(d, 1 \mathrm{H}, \mathrm{Ar}-\mathrm{H}), 6.69(d d$, $2 \mathrm{H}, \mathrm{Ar}-\mathrm{H}), 7.15(t, 1 \mathrm{H}, \mathrm{Ar}-\mathrm{H})$; MS: $m / z 221\left(M^{+}\right)$.

HPLC analysis was performed with a Shimadzu LC 2010 series HPLC system (EMPOWER software) equipped with a quaternary pump and UV detector monitoring the range $200-400 \mathrm{~nm}$. Isomers were analysed on a CHIRALPAK AD-3 $(250 \times 4.6 \mathrm{~mm} \times 5 \mu \mathrm{m})$ column using the normal-phase method, while a reverse-phase HPLC analysis was carried out using INERTSIL ODS-3 V $(4.6 \times 250 \mathrm{~mm} \times$ $5 \mu \mathrm{m})$. The mobile phase was an 85:15 $(\mathrm{v} / \mathrm{v})$ mixture of hexane and tetrahydrofuran, respectively.

Single crystals of all four isomers, (I)-(IV), suitable for X-ray crystallography studies were obtained by cooling hot methanol solutions.

\section{Stereoisomer (I)}

\section{Crystal data}

$\mathrm{C}_{14} \mathrm{H}_{24} \mathrm{NO}^{+} \cdot \mathrm{Cl}^{-}$

$M_{r}=257.79$

Monoclinic, $P 2_{1}$ 。

$a=7.1600(15) \AA$

$b=11.688$ (3) $\AA$

$c=17.514$ (4) $\AA$

$\beta=94.535(3)^{\circ}$

$$
\begin{aligned}
& V=1461.1(5) \AA^{3} \\
& Z=4 \\
& \text { Mo } K \alpha \text { radiation } \\
& \mu=0.25 \mathrm{~mm}^{-1} \\
& T=294 \mathrm{~K} \\
& 0.18 \times 0.15 \times 0.09 \mathrm{~mm}
\end{aligned}
$$

\section{Data collection}

Bruker SMART APEX CCD areadetector diffractometer

Absorption correction: multi-scan (SADABS; Bruker, 2001) $T_{\min }=0.955, T_{\max }=0.976$
14096 measured reflections 5135 independent reflections 4972 reflections with $I>2 \sigma(I)$ $R_{\text {int }}=0.022$ 
Table 1

Selected valence and torsion angles $\left(^{\circ}\right)$ for stereoisomers (I)-(IV).

\begin{tabular}{|c|c|c|c|c|c|c|}
\hline Parameter & (I), molecule $A$ & (I), molecule $B$ & (II), molecule $A$ & (II), molecule $B$ & (III) & (IV) \\
\hline $\mathrm{C} 7-\mathrm{C} 8-\mathrm{C} 9$ & $112.48(16)$ & $114.95(16)$ & $112.59(18)$ & $115.22(19)$ & $112.65(17)$ & $112.78(16)$ \\
\hline $\mathrm{C} 8-\mathrm{C} 7-\mathrm{C} 10$ & $118.80(13)$ & $113.89(13)$ & $111.66(15)$ & $113.99(15)$ & $112.91(13)$ & $112.95(14)$ \\
\hline $\mathrm{C} 1-\mathrm{C} 7-\mathrm{C} 8-\mathrm{C} 9$ & $63.8(2)$ & $170.38(16)$ & $-63.6(2)$ & $-170.38(18)$ & $-59.4(2)$ & $59.4(2)$ \\
\hline $\mathrm{C} 1-\mathrm{C} 7-\mathrm{C} 10-\mathrm{C} 12$ & $63.21(17)$ & $65.15(17)$ & $-63.4(2)$ & $-65.6(2)$ & $170.15(16)$ & $-170.03(15)$ \\
\hline $\mathrm{C} 7-\mathrm{C} 10-\mathrm{C} 12-\mathrm{N} 1$ & $171.87(13)$ & $177.09(13)$ & $-172.03(15)$ & $-176.92(15)$ & $157.87(17)$ & $-157.68(17)$ \\
\hline
\end{tabular}

\section{Refinement}

\section{$R\left[F^{2}>2 \sigma\left(F^{2}\right)\right]=0.027$}

$w R\left(F^{2}\right)=0.072$

$S=1.06$

5135 reflections

331 parameters

1 restraint

$\mathrm{H}$ atoms treated by a mixture of

independent and constrained

refinement

\section{Stereoisomer (II)}

Crystal data

$\mathrm{C}_{14} \mathrm{H}_{24} \mathrm{NO}^{+} \cdot \mathrm{Cl}^{-}$

$M_{r}=257.79$

Monoclinic, $P 2_{1}$

$a=7.160(3) \AA$

$b=11.688(5) \AA$

$c=17.526(8) \AA$

$\beta=94.570(7)^{\circ}$

Table 2

Hydrogen-bond geometry $\left(\AA{ }^{\circ}\right)$ for (I).

\begin{tabular}{lllll}
\hline$D-\mathrm{H} \cdots A$ & $D-\mathrm{H}$ & $\mathrm{H} \cdots A$ & $D \cdots A$ & $D-\mathrm{H} \cdots A$ \\
\hline $\mathrm{N} 1 A-\mathrm{H} 1 \mathrm{~N} \cdots \mathrm{Cl} 1 B^{\mathrm{i}}$ & $0.875(19)$ & $2.23(2)$ & $3.0569(17)$ & $157(2)$ \\
$\mathrm{O} 1 A-\mathrm{H} 1 \mathrm{O} \cdots \mathrm{Cl} 1 A$ & $0.83(3)$ & $2.24(3)$ & $3.0584(17)$ & $168(2)$ \\
$\mathrm{N} 1 B-\mathrm{H} 2 \mathrm{~N} \cdots \mathrm{Cl} 1 A$ & $0.90(2)$ & $2.19(2)$ & $3.0506(15)$ & $158(2)$ \\
$\mathrm{O} 1 B-\mathrm{H} 2 \mathrm{O} \cdots \mathrm{Cl} 1 B$ & $0.79(3)$ & $2.30(3)$ & $3.0667(17)$ & $164(2)$ \\
\hline
\end{tabular}

Symmetry code: (i) $x-1, y, z$.

Table 3

Hydrogen-bond geometry $\left(\AA{ }^{\circ}{ }^{\circ}\right)$ for (II).

\begin{tabular}{lllll}
\hline$D-\mathrm{H} \cdots A$ & $D-\mathrm{H}$ & $\mathrm{H} \cdots A$ & $D \cdots A$ & $D-\mathrm{H} \cdots A$ \\
\hline $\mathrm{O} 1 A-\mathrm{H} 1 \mathrm{O} \cdots \mathrm{Cl} 1 A$ & $0.81(3)$ & $2.26(3)$ & $3.060(2)$ & $169(3)$ \\
$\mathrm{N} 1 A-\mathrm{H} 1 \mathrm{~N} \cdots \mathrm{Cl} 1 B^{\mathrm{i}}$ & $0.88(2)$ & $2.23(2)$ & $3.056(2)$ & $156.5(18)$ \\
$\mathrm{N} 1 B-\mathrm{H} 2 \mathrm{~N} \cdots \mathrm{Cl} 1 A$ & $0.91(3)$ & $2.19(3)$ & $3.051(2)$ & $158.9(19)$ \\
$\mathrm{O} 1 B-\mathrm{H} 2 \mathrm{O} \cdots \mathrm{Cl} 1 B$ & $0.79(3)$ & $2.30(3)$ & $3.067(2)$ & $166(3)$ \\
\hline
\end{tabular}

Symmetry code: (i) $x+1, y, z$.

Table 4

Hydrogen-bond geometry $\left(\AA,^{\circ}\right)$ for (III).

\begin{tabular}{|c|c|c|c|c|}
\hline$D-\mathrm{H} \cdots A$ & $D-\mathrm{H}$ & $\mathrm{H} \cdots A$ & $D \cdots A$ & $D-\mathrm{H} \cdots A$ \\
\hline $\mathrm{N} 1-\mathrm{H} 1 \mathrm{~N} \cdots \mathrm{Cl} 1$ & $0.97(2)$ & $2.13(2)$ & $3.0580(15)$ & $160.5(16)$ \\
\hline $\mathrm{O} 1-\mathrm{H} 1 \mathrm{O} \cdots \mathrm{Cl} 1^{\mathrm{i}}$ & $0.79(3)$ & $2.32(3)$ & 3.1083 (16) & $174(2)$ \\
\hline $\mathrm{C} 11-\mathrm{H} 11 \mathrm{~A} \cdots \mathrm{Cl} 1$ & 0.96 & 2.75 & $3.620(2)$ & 151 \\
\hline $\mathrm{C} 13-\mathrm{H} 13 \mathrm{C} \cdots \mathrm{Cl} 1^{\mathrm{ii}}$ & 0.96 & 2.71 & 3.657 (3) & 168 \\
\hline
\end{tabular}

Symmetry codes: (i) $-x, y+\frac{1}{2},-z-\frac{1}{2}$; (ii) $x-\frac{1}{2},-y+\frac{1}{2},-z$.

\section{Data collection}

Bruker SMART APEX CCD areadetector diffractometer

Absorption correction: multi-scan (SADABS; Bruker, 2001)

$T_{\min }=0.963, T_{\max }=0.986$

\section{Refinement}

$R\left[F^{2}>2 \sigma\left(F^{2}\right)\right]=0.031$

$w R\left(F^{2}\right)=0.075$

$S=1.06$

5139 reflections

331 parameters

1 restraint

$\mathrm{H}$ atoms treated by a mixture of independent and constrained refinement

\section{Stereoisomer (III)}

Crystal data

$\mathrm{C}_{14} \mathrm{H}_{24} \mathrm{NO}^{+} \cdot \mathrm{Cl}^{-}$

$M_{r}=257.79$

Orthorhombic, $P 2_{1} 2_{1} 2_{1}$

$a=8.8218$ (6) $\AA$

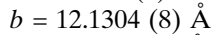

$c=14.0031(9) \AA$

\section{Data collection}

Bruker SMART APEX CCD areadetector diffractometer

Absorption correction: multi-scan (SADABS; Bruker, 2001)

$T_{\min }=0.958, T_{\max }=0.975$

\section{Refinement}

$R\left[F^{2}>2 \sigma\left(F^{2}\right)\right]=0.030$

$w R\left(F^{2}\right)=0.081$

$S=1.03$

2653 reflections

166 parameters

$\mathrm{H}$ atoms treated by a mixture of independent and constrained refinement
13998 measured reflections 5139 independent reflections 4883 reflections with $I>2 \sigma(I)$ $R_{\text {int }}=0.021$

$\Delta \rho_{\max }=0.14 \mathrm{e} \AA^{-3}$

$\Delta \rho_{\min }=-0.10 \mathrm{e}^{-3}$

Absolute structure: Flack \&

Bernardinelli (2000), with 2431

Friedel pairs

Flack parameter: -0.02 (4)

$$
\begin{aligned}
& V=1498.50(17) \AA^{3} \\
& Z=4 \\
& \text { Mo } K \alpha \text { radiation } \\
& \mu=0.24 \mathrm{~mm}^{-1} \\
& T=294 \mathrm{~K} \\
& 0.17 \times 0.14 \times 0.09 \mathrm{~mm}
\end{aligned}
$$

14552 measured reflections 2653 independent reflections 2540 reflections with $I>2 \sigma(I)$ $R_{\text {int }}=0.022$

Table 5

Hydrogen-bond geometry $\left(\AA,^{\circ}\right)$ for (IV).

\begin{tabular}{lllll}
\hline$D-\mathrm{H} \cdots A$ & $D-\mathrm{H}$ & $\mathrm{H} \cdots A$ & $D \cdots A$ & $D-\mathrm{H} \cdots A$ \\
\hline $\mathrm{N} 1-\mathrm{H} 1 \mathrm{~N} \cdots \mathrm{Cl} 1$ & $0.95(2)$ & $2.14(2)$ & $3.0536(15)$ & $161.0(16)$ \\
$\mathrm{O} 1-\mathrm{H} 1 \mathrm{O} \cdots \mathrm{C} 1{ }^{\mathrm{i}}$ & $0.81(3)$ & $2.29(3)$ & $3.1013(15)$ & $175(2)$ \\
$\mathrm{C} 11-\mathrm{H} 11 A \cdots \mathrm{Cl} 1$ & 0.96 & 2.75 & $3.614(2)$ & 151 \\
$\mathrm{C}^{1}-\mathrm{H} 13 B \cdots \mathrm{Cl}{ }^{\mathrm{ii}}$ & 0.96 & 2.71 & $3.651(3)$ & 167 \\
\hline
\end{tabular}

Symmetry codes: (i) $-x+2, y-\frac{1}{2},-z+\frac{5}{2}$; (ii) $x+\frac{1}{2},-y+\frac{3}{2},-z+2$. 


\section{organic compounds}

\section{Stereoisomer (IV)}

\section{Crystal data}

$$
\begin{aligned}
& \mathrm{C}_{14} \mathrm{H}_{24} \mathrm{NO}^{+} \cdot \mathrm{Cl}^{-} \\
& M_{r}=257.79 \\
& \text { Orthorhombic, } P 2_{1} 2_{1} 2_{1} \\
& a=8.8101(6) \AA \\
& b=12.1094(8) \AA \\
& c=13.9784(9) \AA
\end{aligned}
$$

$$
\begin{aligned}
& V=1491.29(17) \AA^{3} \\
& Z=4 \\
& \text { Mo } K \alpha \text { radiation } \\
& \mu=0.24 \mathrm{~mm}^{-1} \\
& T=294 \mathrm{~K} \\
& 0.21 \times 0.17 \times 0.12 \mathrm{~mm}
\end{aligned}
$$

\section{Data collection}

Bruker SMART APEX CCD areadetector diffractometer

Absorption correction: multi-scan (SADABS; Bruker, 2001)

$T_{\min }=0.948, T_{\max }=0.969$

\section{Refinement}

$R\left[F^{2}>2 \sigma\left(F^{2}\right)\right]=0.030$

$w R\left(F^{2}\right)=0.083$

$S=1.05$

2630 reflections

166 parameters

$\mathrm{H}$ atoms treated by a mixture of independent and constrained refinement

All N- and O-bound $\mathrm{H}$ atoms were located in a difference Fourier density map and refined isotropically. All other $\mathrm{H}$ atoms were positioned geometrically and treated as riding on their parent $\mathrm{C}$ atoms, with $\mathrm{C}-\mathrm{H}=0.93-0.98 \AA$, and with $U_{\text {iso }}(\mathrm{H})=1.5 U_{\text {eq }}(\mathrm{C})$ for methyl or $1.2 U_{\text {eq }}(\mathrm{C})$ for other $\mathrm{H}$ atoms. The methyl groups were allowed to rotate but not to tip.

For all compounds, data collection: SMART (Bruker, 2001); cell refinement: SAINT (Bruker, 2001); data reduction: SAINT; program(s) used to solve structure: SHELXS97 (Sheldrick, 2008); program(s) used to refine structure: SHELXL97 (Sheldrick, 2008); molecular graphics: DIAMOND (Brandenburg \& Putz, 2005), PLATON (Spek, 2009) and Mercury (Macrae et al., 2008); software used to prepare material for publication: SHELXL97.

The authors thank Dr J. S. Yadav, Director, IICT, Hyderabad, for his kind encouragement.

Supplementary data for this paper are available from the IUCr electronic archives (Reference: SF3144). Services for accessing these data are described at the back of the journal.

\section{References}

Brandenburg, K. \& Putz, H. (2005). DIAMOND. Release 3.0c. Crystal Impact GbR, Bonn, Germany.

Bruker (2001). SAINT (Version 6.28A), SMART (Version 5.625) and $S A D A B S$. Bruker AXS Inc., Madison, Wisconsin, USA.

Etropolski, M. S., Okamoto, A., Shapiro, D. Y. \& Rauschkolb, C. (2010). Pain Physician, 13, 61-70.

Flack, H. D. \& Bernardinelli, G. (2000). J. Appl. Cryst. 33, 1143-1148.

Franklin, R., Golding, T. \& Tyson, R. G. (2010). US Patent No. 2010/ 0227921A1.

Macrae, C. F., Bruno, I. J., Chisholm, J. A., Edgington, P. R., McCabe, P., Pidcock, E., Rodriguez-Monge, L., Taylor, R., van de Streek, J. \& Wood, P. A. (2008). J. Appl. Cryst. 41, 466-470.

Ravikumar, K. \& Sridhar, B. (2009). Acta Cryst. C65, o502-o505.

Ravikumar, K. \& Sridhar, B. (2010). Acta Cryst. C66, o97-o100.

Reeves, R. R. \& Cox, S. K. (2008). South. Med. J. 101, 193-195.

Sheldrick, G. M. (2008). Acta Cryst. A64, 112-122.

Spek, A. L. (2009). Acta Cryst. D65, 148-155.

Tzschentke, T. M., Christoph, T., Kögel, B., Schiene, K., Hennies, H. H., Englberger, W., Haurand, M., Jahnel, U., Cremers, T. I., Friderichs, E. \& De Vry, J. (2007). J. Pharmacol. Exp. Ther. 323, 265-276. 